\section{Reacción hemolítica transfusional tardía en un paciente con anemia de células falciformes: reporte de un caso}

\author{
FELIPE MOYA ${ }^{2, a}$, MAURICIO RIVERA ${ }^{2, a}$, FERNANDO ARAYA ${ }^{1}$, \\ JAVIERA DONOSO $^{1}$, PABLO SANDOVAL ${ }^{1,3}$, PABLO VARAS $^{1,3}$
}

\section{Delayed hemolytic reaction to transfusion in sickle cell anemia. Report of one case}

Sickle cell anemia was a rare disease in Chile, especially in adults, however the recent immigration wave from Haiti is changing this scenario. We report a 29 year old black female from Haiti with a non-disclosed history of sickle cell anemia. She was transfused with two units of red blood cells, found unconscious and with jaundice five days later and admitted to the hospital. On admission she had a hemoglobin of $3.3 \mathrm{~g} / \mathrm{dL}$, a total bilirubin of $5.08 \mathrm{mg} / \mathrm{dL}$, a LDH of 1,306 Ui/L. She was transfused again, worsening her condition. An alloimmunization and delayed hemolytic reaction was suspected. A direct Coombs test was positive. She was treated with steroids and her serum hemoglobin rose progressively.

(Rev Med Chile 2018; 146: 1347-1350)

Key words: Anemia, Hemolytic; Anemia, Sickle Cell; Duffy Blood-Group System; Emigration and Immigration.
'Servicio de Medicina, Complejo Asistencial Dr. Sótero del Río, Puente Alto. Santiago, Chile. ${ }^{2}$ Escuela de Medicina, Pontificia Universidad Católica de Chile. Santiago, Chile.

${ }^{3}$ Departamento de Medicina Interna, Escuela de Medicina, Pontificia Universidad Católica de Chile. Santiago, Chile. anterno de medicina Facultad de Medicina Pontificia Universidad Católica de Chile. Santiago, Chile.

Los autores declaran no tener conflictos de interés. Trabajo no recibió financiamiento.

Recibido el 20 de agosto de 2018, aceptado el 18 de octubre de 2018.

Correspondencia: Dr. Pablo Varas Arancibia Diagonal Paraguay 362, Oficina 512. Departamento de Medicina Interna, Escuela de Medicina, Pontificia Universidad Católica de Chile. Santiago, Chile. pnvaras@uc.cl
L a ACF es una hemoglobinopatía hereditaria autosómica codominante debido a la mutación del gen que codifica la Beta-globina (Glu6Val) ${ }^{1-3}$ y que se manifiesta como una anemia hemolítica crónica. Suele distribuirse en regiones cálidas tales como África, India, Brasil y el Caribe, en donde la malaria endémica y la migración se han asociado con una mayor prevalencia de esta patología ${ }^{2,4}$.

La presentación homocigota de la enfermedad lleva a la formación de un tetrámero de hemoglobina llamada HbS, "sickle" o "falciforme", que al desoxigenarse polimeriza y lleva al glóbulo rojo (GR) hacia una forma de hoz elongada, menos flexible, que ocluye el lecho capilar precipitando fenómenos vaso-oclusivos. Esto provoca episodios reiterados de isquemia e inflamación, con manifestaciones agudas y crónicas en diferentes órganos. Una vez que la $\mathrm{HbS}$ vuelve a oxigenarse, el eritrocito retorna a su forma bicóncava. Esta constante transformación culmina en un estado falciforme irreversible, de menor vida media por fenómenos hemolíticos intra y extravasculares, desarrollándose así una anemia crónica².

Dentro de las complicaciones agudas destacan las crisis de dolor agudo a nivel de huesos por fenómenos de vaso-oclusión y alteración de la oxigenación e infarto-reperfusión en diferentes órganos. Así, las complicaciones crónicas se deben a reiterados eventos agudos tanto a nivel renal, cerebral, cardíaco, esplénico y otros. Para tratar estas complicaciones, el pilar terapéutico se basa en transfusiones y/o exanguino-transfusiones de GR, llegando a ser requeridas por $90 \%$ de los pacientes al menos una vez en la vida ${ }^{5}$, con riesgos de aloinmunización. La reacción hemolítica transfusional tardía (RHTT) es un ejemplo de ellas ${ }^{2}$.

Los últimos reportes migratorios publicados por el Departamento de Extranjería y Migración de nuestro país muestran un crecimiento constante de la población inmigrante en los últimos años, principalmente colombianos, haitianos y venezo- 
$\operatorname{lanos}^{6,7}$. Esto es un reto tanto para los organismos encargados de los planes migratorios, como para el sistema y personal de salud. La exposición y enfrentamiento a patologías poco frecuentes en la población residente requiere de actualización y adaptación con respecto al diagnóstico y manejo de estas enfermedades. En este reporte se presenta el caso de una paciente haitiana residente en Chile desde 2016 con el antecedente de ACF cursando una RHTT como complicación aguda.

\section{Caso clínico}

Mujer haitiana de 29 años, de raza negra, con el antecedente de una ACF, pero de conocimiento en Chile solo desde el 2017 por limitaciones de idioma. Presenta daño crónico ya establecido de nefropatía médica con proteinuria en rango nefrótico (4,6 g/día), infartos cerebrales antiguos, cardiomegalia severa con fracción de eyección preservada y vertebras con morfología en $\mathrm{H}$ sugerentes de infarto de los platillos vertebrales. Politransfundida durante el proceso diagnóstico, luego se prescribe hidroxiurea y se mantiene con buen seguimiento ambulatorio. En un último control presenta hemoglobina $(\mathrm{Hb}) 5,5 \mathrm{~g} / \mathrm{dL}$, lactato deshidrogenasa (LDH) $868 \mathrm{U} / \mathrm{L}$, bilirrubina total (BT) $2,78 \mathrm{mg} / \mathrm{dL}$, siendo transfundida con 2 unidades de GR sin incidentes inmediatos. Cinco días después es encontrada comprometida de conciencia e ictérica, siendo trasladada al servicio de urgencias del Complejo Asistencial Dr. Sótero del Río. Ingresa en sopor superficial, mal perfundida, hipotensa (93/51 mmHg), taquicárdica (109lpm), febril $\left(39^{\circ} \mathrm{C}\right)$, con requerimientos de $\mathrm{O}_{2}$ a $35 \%$ para saturar 94\%, mucosas pálidas, ictérica, con importante hepatoesplenomegalia, sin otros hallazgos. Sus exámenes de ingreso mostraron $\mathrm{Hb} 3,3 \mathrm{~g} / \mathrm{dL}$, leucocitos $19,07 \times 10^{3} / \mathrm{uL}$, BT 5,08 mg/dL, directa 2,54 mg/dL, LDH $1306 \mathrm{UI} / \mathrm{L}$, creatinina 1,31 mg/ $\mathrm{dL}, \mathrm{BUN} 45 \mathrm{mg} / \mathrm{dL}$, lactato $18 \mathrm{mg} / \mathrm{dL}(\mathrm{VN}<19 \mathrm{mg} /$ dL) y proteína C reactiva $68 \mathrm{mg} / \mathrm{L}(\mathrm{VN}<5 \mathrm{mg} / \mathrm{dL})$.

El cuadro es interpretado como una crisis hemolítica de ACF y anemia severa, indicándose una nueva transfusión de 4 unidades de GR, evolucionando con mayor deterioro clínico, disminución de $\mathrm{Hb}$ a 2,8 g/dL y deterioro de función renal (lactato $33,8 \mathrm{mg} / \mathrm{dL}$, pH 7,23, $\mathrm{HCO}_{3} 11,6$ $\mathrm{mEq} / \mathrm{L}$, creatinina $4,96 \mathrm{mg} / \mathrm{dL}$ y BUN $119 \mathrm{mg} /$ $\mathrm{dL}$ ), requiriendo terapia de reemplazo renal en dos oportunidades. Una vez descartado el origen infeccioso y otras complicaciones de la ACF se planteó el diagnóstico de síndrome hiperhemolítico por aloinmunización, prescribiéndose hidratación abundante con suero hipotónico (SF $0,45 \%)$ y metilprednisolona $1 \mathrm{~g}$ ev, seguido de prednisona $2 \mathrm{mg} / \mathrm{kg} / \mathrm{d}$. Desde el banco de sangre se informa un Coombs directo positivo, así como reacción cruzada frente a todas las unidades de GR disponibles, debiendo prescindir de las transfusiones. Así, tras el inicio de esteroides presenta una mejoría progresiva de $\mathrm{Hb}: 2,7 \mathrm{~g} / \mathrm{dL}$ al $3^{\circ}$ día, 2,9 $\mathrm{g} / \mathrm{dL}$ al $5^{\circ}, 4,5 \mathrm{~g} / \mathrm{dL}$ al $12^{\circ}$ día y $5,8 \mathrm{~g} / \mathrm{dL}$ al $20^{\circ}$ día. De forma paralela recupera el estado de conciencia y normaliza función renal.

Por sospecha de una RHTT se le solicitó al Instituto de Salud Pública la fenotipificación de eritrocitos, detectándose la presencia de anticuerpos Anti-Fy3, dirigidos contra el sistema Duffy, sugiriéndose que ante nuevos requerimientos transfusionales se ubicaran donantes de raza negra.

Finalmente, la paciente evoluciona con niveles estables de $\mathrm{Hb}$ (entre 5,0-5,5 g/dL) bajo terapia corticoesteroidal, hidroxiurea, ácido fólico, vitamina B12 y eritropoyetina bisemanal, decidiéndose el alta.

\section{Discusión}

En este caso, tanto los antecedentes (raza negra y politranfusiones) como la evolución (SIRS, exacerbación de la anemia e incremento de LDH) al cuarto día post transfusión, apoyan el diagnóstico de un fenómeno hemolítico aloinmune, específicamente de RHTT. Es precisamente en este escenario donde se debe tener un alto grado de sospecha, ya que, a pesar de ser una complicación poco frecuente en nuestro medio, es severa y de riesgo vital ${ }^{2,8}$.

La aloinmunización es un efecto adverso de las transfusiones, donde anticuerpos del receptor reconocen antígenos ubicados en la superficie de los GR transfundidos ${ }^{9}$. La RHTT es un ejemplo poco frecuente pero severo, especialmente en pacientes expuestos a múltiples transfusiones en su vida ${ }^{10}$, algo frecuente en la ACF. Se estima que la tasa de aloinmunización en ACF puede llegar a ser de hasta $47 \%{ }^{11}$, con una incidencia de RHTT de $1-19 \%{ }^{8}$. Los factores que se asocian a mayor 
aloinmunización son: la cantidad de transfusiones previas, una primera transfusión a mayor edad y sexo femenino (mayor frecuencia de transfusión $)^{12}$. En esta, se produce tanto la destrucción de GR del donante como del receptor por mecanismos aún no completamente esclarecidos ${ }^{10,13} \mathrm{y}$ clínicamente se manifiesta como anemia severa con caída de la hemoglobina pre-transfusional, dolor óseo, fiebre y signos de hemólisis (ictericia), además de un laboratorio compatible (LDH elevada, hiperbilirrubinemia, haptoglobina baja y hemoglobinuria $)^{13}$. El punto más importante para el diagnóstico es reconocer la temporalidad de los síntomas respecto de la transfusión, que se inicia en promedio, a los 7 días después de esta (rango entre 4 y 11 días) $)^{14}$.

El estudio de identificación de anticuerpos irregulares, arrojó la identificación de anticuerpos Anti Fy3, que reconoce los eritrocitos que expresan los antígenos Fya+ y/o Fyb+ del sistema Duffy, involucrado principalmente en las reacciones hemolíticas transfusionales tardías ${ }^{15}$.

Este fenotipo es muy frecuente en caucásicos y escaso en raza negra. Visto de otra manera, menos de $1 \%$ de los caucásicos tiene fenotipo Fy (a-b-) al compararlo con una frecuencia mayor al $70 \%$ en raza negra, no siendo extraño este fenotipo en pacientes con $\mathrm{ACF}^{16}$. La glicoproteína Duffy es de vital importancia en esta población ya que es usada por el Plasmodium vivax para su unión a los GR e infestación, por lo tanto, la ausencia total de estos antígenos confiere resistencia al parásito como medida adaptativa frente a la endemia de malaria.

En este caso, la positividad para las pruebas de reacción cruzada frente a toda la reserva del banco de sangre de nuestro centro puso en evidencia la dificultad para conseguir unidades de GR, tanto por la escasa probabilidad de hallar unidades Fy (a-b-) en los donantes habituales como por la dificultad para encontrar donantes del mismo grupo étnico que califiquen como tal. Según la norma general técnica que regula el procedimiento de atención de donantes de sangre en nuestro país, se prohíbe la presencia de terceras personas durante la entrevista de selección de donantes, incluyendo traductores ${ }^{17}$, lo que dificulta la donación de población extranjera. Estas dificultades se acentúan al requerirse una gran cantidad de unidades como las necesarias para una exanguíneo-transfusión o en un escenario de urgencia.

Con respecto al manejo de los pacientes que cursan con RHTT, se deben evitar las transfusiones a las estrictamente necesarias. El uso de suero hipotónico permite optimizar la hidratación del GR, llevándolo a un estado tridimensional más fisiológico, evitando así la aparición de nuevas complicaciones agudas de $\mathrm{ACF}^{18}$. Además, se debe administrar terapia inmunosupresora consistente en altas dosis de corticoesteroides y, en casos severos, inmunoglobulina intravenosa o rituximab ${ }^{11}$.

\section{Conclusiones}

Ante los nuevos cambios migratorios debemos de adaptarnos a la aparición de enfermedades infrecuentes en nuestro medio. En la ACF debemos conocer sus manifestaciones y complicaciones. En lo que respecta a la aloinmunización, el equipo médico tiene un rol fundamental en su prevención, detección anticipable y tratamiento. Así mismo, el sistema de salud y los bancos de sangre deben de adaptarse a estos cambios poblacionales para poder responder a las nuevas demandas, en este caso, las transfusionales.

\section{Referencias}

1. Beutler E. Disorders of Hemoglobin Structure: Sickle Cell Anemia and Related Abnormalities. En: Lichtman M, Beutler E, Kaushansky K, Kipps T, Seligsohn U, Prchal J, editores. Williams Hematology, Seventh edition. Mc Graw Hill Companies Inc. USA, 2006. pp. 667-780.

2. Ware RE, de Montalembert M, Tshilolo L, Abboud MR. Sickle cell disease. Lancet 2017; 390 (10091): 311-23.

3. Kato G, Piel F, Reid C, Gaston M, Ohene-Frempong K, Krishnamurti L, et al. Sickle cell disease. Nature Reviews Disease Primers 2018; 4: 18010.

4. Williams TN. Human red blood cell polymorphisms and malaria. Curr Opin Microbiol 2006; 9: 388-94.

5. Chou ST. Transfusion therapy for sickle cell disease: a balancing act. Hematology Am Soc Hematol Educ Program 2013; 2013: 439-46.

6. DEM (2016). Boletín Informativo $\mathrm{N}^{\circ} 1$ : Migración Haitiana en Chile. Departamento de Extranjería y Migración, Santiago de Chile. Disponible en: http://www. extranjeria.gob.cl/media/2016/09/boletin-1.pdf

7. DEM (2017). Reportes Migratorios: Población Migrante en Chile. Departamento de Extranjería y Migración, Santiago de Chile. Disponible en: http://www.extranjeria.gob.cl/media/2017/09/RM_PoblacionMigranteChile. pdf 
8. Garratty G. What do we mean by "hyperhaemolysis" and what is the cause? Transfus Med 2012; 22 (2): 77 9.

9. Aygun B, Padmanabham S, Paley C, Chandrasekaran V. Clinical significance of RBC alloantibodies and autoantibodies in sickle cell patients who received transfusions. Transfusion 2002; 42 (1): 37-43.

10. Win N, Doughty H, Telfer P, Wild BJ, Pearson TC. Hyperhemolytic transfusion reaction in sickle cell disease. Transfusion 2001; 41 (3): 323-8.

11. McGlennan AP, Grundy EM. Delayed haemolytic transfusion reaction and hyperhaemolysis complicating peri-operative blood transfusion in sickle cell disease. Anaesthesia 2005; 60 (6): 609-12.

12. Scheunemann L, Ataga K. DelayedHemolyticTransfusionReaction in Sickle Cell Disease. The American Journal of the Medical Sciences 2010; 339 (3): 266-9.

13. Win N. Hyperhemolysis syndrome in sickle cell disease. Expert Rev Hematol 2009; 2 (2): 111-5.

14. Talano JA, Hillery CA, Gottschall JL, Baylerian DM,
Scott JP. Delayed hemolytic transfusion reaction/hyperhemolysis syndrome in children with sickle cell disease. Pediatrics 2003; 111 (6 Pt 1): e661-5.

15. Dean L. Blood Groups and Red Cell Antigens [Internet]. Bethesda (MD): National Center for Biotechnology Information (US); 2005. Chapter 9, The Duffy blood group. Available from: https://www.ncbi.nlm.nih.gov/ books/NBK2271/

16. Went R, Wright J, Webster R, Stamps R. Anti-Fy3 in sickle cell disease: a difficult transfusion problem. British Journal Haematology 2009; 144 (4): 621-2.

17. Norma general técnica $\mathrm{N}^{\circ} 0146$, que regula el procedimiento de atención de donantes de sangre (en sitio fijo o móvil). Subsecretaría de redes asistenciales del MINSAL. Disponible en http://www.hematologia.org/ bases/arch1087.pdf

18. Field MD. Overview of the management and prognosis of sickle cell disease. UpToDate. Waltham, MA: UpToDate Inc. http://www.uptodate.com (Accedido el 1 de julio de 2018). 